\title{
El mito de Esparta. Un itinerario por la cultura occidental
}

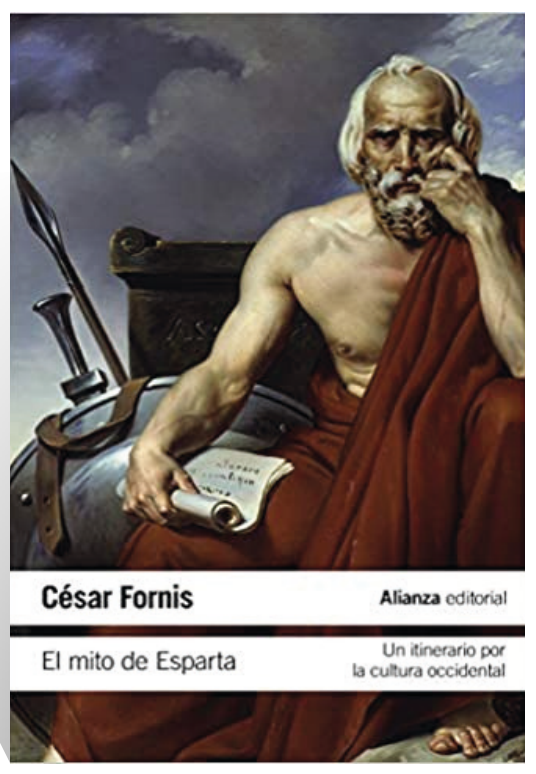

FICHA BIBLIOGRÁFICA

CÉsAr Fornis VAquero, El mito de Esparta. Un itinerario por la cultura occidental. Madrid, Alianza Editorial, 2019, 386 págs. ISBN: 978-84-9181-612-6.

$\mathrm{M}^{\mathrm{a}}$ del Mar Rodríguez Alcocer

EL Mito DE ESPARTA RELATA LA LEYENDA que se ha creado en torno a Esparta y los espartanos. Dicho de otra manera, este libro trata el desarrollo de un reflejo distorsionado que, a lo largo de la historia occidental, ha influido en gran cantidad de políticos, teóricos, filósofos, literatos, artistas e incluso en la cultura popular, lo que ha dado lugar a una imagen de la polis de los lacedemonios muy inmovilista y extremadamente condicionada por lo que François Ollier llamó el mirage espartiata.

Este trabajo de César Fornis Vaquero, catedrático de Historia Antigua de la Universidad de Sevilla, se puede considerar una actualización y ampliación de los estudios de Ollier en tanto que el foco de atención no es lo que realmente fue la sociedad espartana, sino lo que los no 
espartanos de la Antigüedad y todos aquellos que les sucedieron en el tiempo creyeron que fue. De esta manera, se aúna en un solo libro todo un conglomerado de estudios en torno a la actual línea de investigación de César Fornis, la recepción y la imagen de Esparta desde la Antigüedad hasta nuestros días. De hecho, el libro se organiza de forma cronológica aunque dejando para el final ciertos temas monográficos que requieren una mirada más global que cronológica, como son la cuestión de género, el hilotismo, o el tema de Leónidas y las Termópilas.

Aunque la temática es compleja y, sobre todo, extremadamente amplia, la obra no es inmensa sino bastante asequible para cualquier tipo de lector. Se percibe claramente que el formato de bolsillo y la editorial elegida para la publicación tienen como objetivo acercar una cuestión candente en la bibliografía actual sobre Esparta a un público más extenso que el meramente investigador. Esto también es evidente en la limitación de las notas a las fuentes antiguas y de la bibliografía a los estudios más relevantes sobre el asunto. No obstante, no por tener unos objetivos que se salen del ámbito científico pierde exactitud metodológica. El orden de la exposición, las ideas que se presentan y la ingente cantidad de referencias documentales hacen de esta obra un tratado exhaustivo y bien organizado que aporta una imagen integral del tema.

Aunque la organización cronológica podría presagiar el comienzo del libro en el arcaísmo, el primer capítulo está dedicado a la época clásica, momento de la pugna por la hegemonía en Grecia y del inicio de la idealización de Esparta. Se ponen en contexto todos los clichés que el resto de los griegos asociaron a los espartanos, dando relevancia al contexto sociopolítico y cultural en el que los distintos autores los crearon y enfatizando el carácter filolaconio o antilaconio de cada autor. Este capítulo es clave para comprender todo lo que va a seguir en los siguientes porque la mayoría de las instituciones y tradiciones laconias que se mencionan aquí, como la paideia, la educación física, el modo de vida (diaita), el concepto de libertad, la relación con la guerra, o la constitución mixta, ayudan a comprender por qué los espartanos se erigieron como modelo de comportamiento para otras tantas sociedades posteriores.

Aunque los fundamentos ideológicos del espejismo se encuentren en época clásica, el autor dedica el segundo capítulo a la memoria social de la comunidad y a cómo se retrotraen en el tiempo figuras o instituciones muy probablemente inventadas en época clásica o tardoarcaica con el fin de construir una imagen de inmutabilidad. Licurgo y la Gran Retra son fundamentales en este sentido porque explican la estabilidad de la sociedad, convirtiéndose en las piedras angulares de la llamada constitución mixta que surgirá constantemente en las obras de los filósofos y teóricos políticos desde época clásica hasta el siglo XX. También ocurre algo parecido con la idea del perfecto ciudadano-hoplita, disciplinado, patriota y superior en el combate, cuyo origen los griegos remontaban a Tirteo cuando realmente fueron Heródoto y Simónides de Ceos las figuras que mejor contribuyeron a su creación gracias al carácter épico que infundieron a ciertos momentos como la batalla de las Termópilas.

El tercer capítulo, dedicado al helenismo y a Roma, tiene una organización parecida al anterior. Primero relata los aspectos que fueron utilizados como referentes espartanos para luego mencionar brevemente la realidad de la Esparta postclásica, una comunidad griega como otras tantas de época helenística pero que miraba hacia atrás para intentar mantener la gloria pasada y sacar rédito de la misma. En este momento César Fornis vuelve nuevamente a la cuestión de la constitución espartana pero en este caso como ejemplo para una Roma que, vista por Polibio, Cicerón o Dioniso de Halicarnaso, no sólo superó la constitución espartana 
sino que se convirtió en garante de las virtudes espartiatas. Es precisamente esta cuestión de la práctica de la virtud uno de los aspectos que más llamó la atención de los moralistas y filósofos helenístico-romanos. En este sentido, quizás el autor que más ha influido en la perspectiva moralizante de Esparta es Plutarco, al que se dedica un buen número de páginas. En cierto modo, la preeminencia que tiene Plutarco en la creación del mirage eclipsa a los otros autores que también merecerían más líneas. Por ejemplo, se menciona el neoplatonismo y el uso de Esparta como exemplum moral, tema menos conocido y que, por esta misma razón, sería de gran interés profundizar en él, entre otras razones, porque podría dar pie al análisis de la influencia de la moralidad laconia en época medieval unida a esta corriente filosófica.

El medievo, desgraciadamente, está representado en apenas dos páginas debido al abandono que sufrió el clasicismo en estos siglos, según el autor, aunque probablemente también tenga mucho que ver el escaso conocimiento que tenemos de fuentes bizantinas de la región de Laconia, a pesar de la importancia del enclave bizantino de Mistras.

En oposición al Medievo, el autor profundiza en el Renacimiento dando una sensación de continuidad con las ideas que se habían potenciado en época romana porque las virtudes y la organización constitucional vuelven a ser los elementos centrales de los tratadistas que trabajaban, bien sobre la educación de los príncipes o bien sobre la mejor forma de gobierno. La dualidad entre pervivencia de ciertos clichés y la aparición de otros nuevos es constante en la obra. Queda claro que la comparación de Esparta con Venecia fue innegable, especialmente en Maquiavelo y otros tratadistas, aunque no solamente las repúblicas italianas hicieron uso de Esparta sino también en la Francia de la que hablaba Montaigne o en la Inglaterra de los Tudor, que utilizó la forma lacedemonia como ejemplo a seguir por el parlamento y la monarquía británicos. En sentido contrario, también los monarcómanos y otros partidarios de frenar el poder real hicieron uso de Esparta al ensalzar el eforado o al poner por encima del rey las leyes. Unos u otros asumían ciertas instituciones como ejemplo a seguir, tanto para encumbrar el poder monárquico como para todo lo contrario, pero dentro siempre de una senda moralizante de influencia plutarquea y platónica que pervivieron posteriormente en la Ilustración.

De hecho, es posiblemente el siglo XVIII el que más profundamente está representado en el libro y esto es porque a partir de ese momento nació una nueva forma de ver el mundo y, con él, la propia Esparta. Temas como la moralidad y el respeto por las leyes persistieron pero adquirieron particular importancia la patria, la libertad (con la crítica al hilotismo) y la igualdad (Mably, Helvétius, Rousseau). De la misma manera en aquel momento surgió la comparación Atenas-Esparta en autores como Voltaire que alababa una Atenas humanista y esplendorosa frente a la austeridad laconia que esclavizaba a los ciudadanos.

A este capítulo 5, centrado en la política, le sigue la contrapartida cultural del capítulo 6 donde César Fornis examina la influencia de Esparta en la literatura y el arte. Se echa de menos alguna imagen que permita visualizar las ideas del autor como sí es posible hacer con los textos. La primera parte se dedica a la literatura donde se percibe el especial protagonismo de Agis IV y Cleómenes III como paradigma de reyes reformadores en las obras de los autores británicos y franceses. Su contrapunto son las obras alemanas centradas en las virtudes y el patriotismo con especial protagonismo de Leónidas o Menelao. En el ámbito artístico, sin embargo, las pinturas francesas se acercan más a los principios políticos 
y menos a los literarios que caracterizan la época dando especial relevancia a Licurgo, las Máximas plutarqueas o al propio Leónidas.

En la misma línea que el capítulo 5, el 7 vuelve a la utilidad política de Esparta pero en el contexto de la independencia de Estados Unidos donde la influencia del mirage fue mucho menor que en Francia porque Roma parecía un mejor ejemplo a seguir. En la comparación entre ambas comunidades generalmente se sublimaba el sistema romano frente al espartano. No obstante la estabilidad institucional de Esparta se percibía como algo positivo frente a los excesos, el imperialismo y la volubilidad de una Atenas clásica que tuvo algo más de peso en Francia desde la Ilustración, lo que no significó, sin embargo, un abandono de Esparta como modelo; es más, las páginas siguientes se centran en el uso que hicieron de Esparta los jacobinos, enfatizando las cuestiones de la virtud ancestral, la austeridad, el espíritu de sacrificio y la igualdad extrema. Todas estas ideas fueron, a ojos de los revolucionarios, impulsadas por un Licurgo que, al hacer a los individuos iguales, limitar el lujo y fomentar la moralidad, había conseguido llevar a los espartiatas a la libertad.

Andando en el tiempo, el siguiente capítulo no podría estar dedicado a otra cosa que no fuera la presencia de Esparta en el siglo XIX y las primeras décadas del XX. En él César Fornis estudia la presencia del mirage en el Romanticismo y el nacimiento del liberalismo, aunque también hace un breve excursus sobre los primeros estudios historiográficos y antropológicos (Jeanmaire, Toynbee), precisamente por su relevancia incluso a día de hoy. Esparta en el siglo XIX quedó un tanto apartada en favor de Roma y, especialmente, de Atenas (gracias a George Grote o Victor Duruy), cuya democracia se convirtió en el mejor ejemplo de las nacientes naciones liberales. Ante este resurgimiento glorioso de Atenas, Esparta quedó en cierto modo relegada a ser el ejemplo de las oposiciones conservadoras a los regímenes liberales, salvo en Alemania donde la obra de Karl Müller, Die Dorier, se convirtió en la base de las teorías sobre el estado racial dibujando una Esparta militarizada, unitaria y disciplinada. También en Francia Maurice Barrès fue precursor del nacionalsocialismo por sus posturas eugenésicas.

Estas dos obras, aunque especialmente la de Müller, fueron básicas para el Nazismo, al que se dedica el capítulo 10. Probablemente la influencia de Esparta en el Nazismo sea de las mejor conocidas gracias al interés morboso que ha generado este régimen atroz y, sobre todo, debido a la puesta en práctica (o la pretensión de hacerlo) de las teorías que se planteaban como la lectura de Tirteo en el campo de batalla, el programa eugenésico (Lebensborn) y educativo o incluso la propuesta que nunca se llevó a cabo de hilotizar a los rusos, todas ellas mencionadas en la obra. Lo más interesante, sin embargo, es que plantea el acercamiento o el rechazo de los grandes investigadores del momento como Wilamowitz-Möllendorf o Wegner Jaeger, y de otros posteriores, viendo cómo la fuerza de la propaganda nazi influyó (y sigue influyendo) en una nueva visión de Esparta muy condicionada por perspectivas totalitarias. La presencia desde el capítulo anterior de algunos nombres de la historiografía más conocida sobre Esparta es realmente útil, especialmente para alumnos universitarios, porque ayuda a comprender mejor el contexto y la lógica de los textos de estos investigadores.

A partir de este momento se suceden cuatro capítulos temáticos. El primero de ellos está dedicado a la cuestión de género, empezando por el uso de Simone de Beauvoir de las mujeres espartanas como modelo de mujer liberadas de las ataduras familiares para seguir con Judith Sargent Murray, una de sus precedentes un siglo y medio antes. El resto del 
capítulo se dedica a la doble perspectiva de las espartanas en época clásica y helenística, por una parte en su faceta de mujeres virtuosas que ponen por encima de su interés el de la patria y, por otra parte, en la crítica que hicieron las fuentes antilaconias que hablaban de las espartanas como mujeres licenciosas o demasiado poderosas. Se echa en falta algo en la mitad que complete la imagen de las espartanas al menos en el pensamiento feminista como, por poner un ejemplo, la reivindicación que hace Mary Wollstonecraft del deporte femenino que se parece mucho a las explicaciones plutarqueas sobre por qué Licurgo hizo que las mujeres se ejercitaran.

No ocurre lo mismo con la cuestión del hilotismo que, aunque breve, muestra una imagen distinta de las críticas al hilotismo que ya se habían presentado anteriormente. Aquí percibimos la visión de los oprimidos, comenzando por la perspectiva escocesa e irlandesa que se veían como hilotas mesenios frente a los espartiatas británicos y pasando también por el movimiento obrero que se comparó con el hilotismo.

El penúltimo capítulo monográfico es mucho más amplio que el anterior y está plagado de referencias porque es cierto que, al menos tras la llegada de 300 al cine, Esparta ha renacido de forma muy vigorosa en todo tipo de formatos populares como los videojuegos o nuevos cómics. La cultura popular del siglo XX y lo que llevamos del XIX ha generado gran cantidad de material, no sólo por 300, sino por la existencia de otras tantas películas, cómics y libros anteriores que se inspiraron en Esparta, sobre todo en la batalla de las Termópilas. El capítulo enumera y examina desde cine, series, cuentos o libros hasta la Spartan Race o el Spartathlon, una ultramaraton que recorre los $246 \mathrm{~km}$ que separan Atenas de Esparta. El número de referencias en este capítulo es abrumador, especialmente si lo comparamos de los precedentes. La cantidad de citas darían para abrir nuevas vías de investigación por cada formato que se expone.

Finalmente, el último capítulo se centra en Leónidas y las Termópilas, aunque parece más bien un homenaje a Heródoto y a Simónides porque está plagado de poemas y textos que encumbran lo ocurrido en las Termópilas y que, si no fuera por la forma en la que lo relatan estos dos autores clásicos, no se habría convertido en un topos literario y ejemplo para cualquier nacionalismo moderno. Aparte del valor que el hecho en sí ha tenido para culturas posteriores, seguramente que lo más significativo de este capítulo es la presencia del estado griego moderno en él. Se echa en falta en ocasiones que apenas ninguna sección se refiera a la influencia que pueda haber tenido Esparta a lo largo de la turbulenta historia griega.

El final es un epílogo que concluye con la negación del mito por parte de los investigadores. Como si fuera una metáfora del angosto nicho académico, apenas 5 páginas recogen las intenciones de los historiadores modernos de intentar borrar el reflejo frente a un mito inmenso, fortalecido cada día más por los medios de masas y que se ha convertido en un elemento más de análisis histórico.

En definitiva, El mito de Esparta promete ser un trabajo útil para sectores muy distintos que se pueden beneficiar de él, tanto investigadores, como alumnos u otros lectores interesados en Esparta que hasta el momento habían devorado en formato divulgativo, novelesco o cinematográfico clichés sobre la sociedad lacedemonia sin plantearse su veracidad o el origen de estos. 